\title{
The 2018 European Heart Rhythm Association Practical Guide on the use of non-vitamin K antagonist oral anticoagulants in patients with atrial fibrillation: executive summary
}

Jan Steffel ${ }^{1}$, Peter Verhamme ${ }^{2}$, Tatjana S. Potpara ${ }^{3}$, Pierre Albaladejo ${ }^{4}$, Matthias Antz ${ }^{5}$, Lien Desteghe ${ }^{6}$, Karl Georg Haeusler ${ }^{7}$, Jonas Oldgren ${ }^{8}$, Holger Reinecke ${ }^{9}$, Vanessa Roldan-Schilling ${ }^{10}$, Nigel Rowell ${ }^{11}$, Peter Sinnaeve ${ }^{2}$, Ronan Collins ${ }^{12}$, A. John Camm ${ }^{13}$, and Hein Heidbüchel ${ }^{6,14}$

Advisors: Martin van Eickels, M.D. (Bayer Healthcare), Jutta Heinrich-Nols, M.D. (Boehringer Ingelheim), Markus Müller, M.D., Ph.D. (Pfizer), Wolfgang Zierhut, M.D. (Daiichi-Sankyo), and Poushali Mukherjea, Ph.D. (Bristol-Myers Squibb)

ESC Scientific Document Group: Gregory Y. H. Lip (EHRA Review Coordinator; UK, Denmark), Jeffrey Weitz (Canada), Laurent Fauchier (France), Deirdre Lane (UK), Giuseppe Boriani (Italy), Andreas Goette (Germany), Roberto Keegan (LAHRS President 2017-2018 (former SOLAECE), Argentina), Robert MacFadyen (Australia), Chern-En Chiang (Taiwan), Boyoung Joung (Korea), and Wataru Shimizu (Japan)

\footnotetext{
${ }^{1}$ Department of Cardiology, University Heart Center Zurich, Rämistrasse 100, CH-8091 Zurich, Switzerland; ${ }^{2}$ Department of Cardiovascular Sciences, University of Leuven, Belgium; ${ }^{3}$ School of Medicine, Belgrade University, Belgrade, Serbia; ${ }^{4}$ Grenoble-Alps University Hospital, Grenoble, France; ${ }^{5}$ City Hospital Braunschweig, Braunschweig, Germany; ${ }^{6}$ Faculty of Medicine and Life Sciences, Hasselt University, Hasselt, Belgium; ${ }^{7}$ Center for Stroke Research Berlin and Department of Neurology, Charité - Universitätsmedizin Berlin; ${ }^{8}$ Uppsala Clinical Research Center and Department of Medical Sciences, Uppsala University, Uppsala, Sweden; ${ }^{9}$ Department of Cardiovascular Medicine, University Hospital Münster, Münster, Germany; ${ }^{10}$ University of Murcia, Murcia, Spain; ${ }^{11}$ Middlesbrough, UK; ${ }^{12}$ Age-Related Health Care \& Stroke-Service, Tallaght Hospital, Dublin, Ireland; ${ }^{13}$ Cardiology Clinical Academic Group, Molecular \& Clinical Sciences Institute, St George's University, London, UK; Imperial College; and ${ }^{14}$ Antwerp University and University Hospital, Antwerp, Belgium
}

Received 26 February 2018; editorial decision 27 February 2018; accepted 1 March 2018; online publish-ahead-of-print 19 March 2018

The current manuscript is the Executive Summary of the second update to the original Practical Guide, published in 2013. Non-vitamin K antagonist oral anticoagulants (NOACs) are an alternative for vitamin $\mathrm{K}$ antagonists (VKAs) to prevent stroke in patients with atrial fibrillation (AF), and have emerged as the preferred choice, particularly in patients newly started on anticoagulation. Both physicians and patients are becoming more accustomed to the use of these drugs in clinical practice. However, many unresolved questions on how to optimally use these agents in specific clinical situations remain. The European Heart Rhythm Association (EHRA) set out to co-ordinate a unified way of informing physicians on the use of the different NOACs. A writing group identified 20 topics of concrete clinical scenarios for which practical answers were formulated, based on available evidence. The 20 topics are (i) eligibility for NOACs; (ii) practical start-up and follow-up scheme for patients on NOACs; (iii) ensuring adherence to prescribed oral anticoagulant intake; (iv) switching between anticoagulant regimens; (v) pharmacokinetics and drug-drug interactions of NOACs; (vi) NOACs in patients with chronic kidney or advanced liver disease; (vii) how to measure the anticoagulant effect of NOACs; (viii) NOAC plasma level measurement: rare indications,

* Corresponding author. Tel: +41 4425515 15; fax: +41 44255 8701. Email address: j.steffel@gmx.ch

Published on behalf of the European Society of Cardiology. All rights reserved. (c) The Author(s) 2018. For permissions, please email: journals.permissions@oup.com. 
precautions, and potential pitfalls; (ix) how to deal with dosing errors; ( $x$ ) what to do if there is a (suspected) overdose without bleeding, or a clotting test is indicating a potential risk of bleeding; (xi) management of bleeding under NOAC therapy; (xii) patients undergoing a planned invasive procedure, surgery or ablation; (xiii) patients requiring an urgent surgical intervention; (xiv) patients with AF and coronary artery disease; (xv) avoiding confusion with NOAC dosing across indications; (xvi) cardioversion in a NOAC-treated patient; (xvii) AF patients presenting with acute stroke while on NOACs; (xviii) NOACs in special situations; (xix) anticoagulation in AF patients with a malignancy; and ( $x x)$ optimizing dose adjustments of VKA. Additional information and downloads of the text and anticoagulation cards in different languages can be found on an EHRA web site (www.NOACforAF.eu).

Keywords Non-vitamin $\mathrm{K}$ antagonist oral anticoagulants $\bullet$ Vitamin $\mathrm{K}$ antagonist $\bullet$ Atrial fibrillation $\bullet$ Stroke

\section{Introduction}

The proper use of non-vitamin $\mathrm{K}$ antagonist (VKA) oral anticoagulants (NOACs) for stroke prevention in patients with atrial fibrillation (AF) requires a diligent approach in various settings of daily clinical practice. ${ }^{1}$ This Practical Guide, as its predecessors from 2013 and 2015, supplements the Guidelines, providing guidance on how to use NOACs in specific clinical situations. ${ }^{1-3}$ In some instances, the authors opted to make recommendations that do not fully align with all SmPCs, with the goal to provide more uniform and simple practical advice. The main pointers of the 2018 version of the European Heart Rhythm Association (EHRA) Practical Guide are summarized in this Executive Summary. The full text of the Update is published in the European Heart Journal. ${ }^{4}$ The 2018 EHRA Practical Guide will also be presented in a new version of the slide kit (downloadable for free by EHRA members) and a Key Message booklet, which can be obtained through EHRA and the European Society of Cardiology (ESC). The reader is referred to visit www.NOACforAF.eu for up-to-date information, where also feedback can be provided.

\section{Eligibility for non-vitamin $\mathrm{K}$ antagonist oral anticoagulants}

Strictly, the term 'non-valvular AF' refers to AF in the absence of a mechanical prosthetic heart valve or moderate to severe mitral stenosis (usually of rheumatic origin). ${ }^{5-9}$ The term 'non-valvular' has been eliminated in the 2016 ESC guidelines on the management of patients with AF and is also not used anymore in this practical guide. ${ }^{5,7}$ Indeed, all other native valvular stenoses and insufficiencies as well as a moderately sized group of patients after mitral valve repair and bioprosthetic valve replacements were included in the pivotal NOAC trials in which they demonstrated a comparable relative efficacy and safety vs. warfarin in patients with vs. without valvular disease (except for a higher risk of bleeding with rivaroxaban vs. warfarin in patients with valvular heart disease in a post hoc analysis of the ROCKET-AF trial). ${ }^{7,10-15}$ Non-vitamin $\mathrm{K}$ antagonist oral anticoagulants may therefore be used in such patients. ${ }^{5,7,16}$ One exception may be $A F$ in the presence of a biological mitral prosthesis implanted for rheumatic mitral stenosis. Although mitral valve flow is normalized post-mitral valve replacement in these patients, their atria usually remain large and severely diseased. As such, VKA may be the preferred option over NOACs in these patients, but more data are needed. In hypertrophic (obstructive) cardiomyopathy, there is limited experience with NOACs but from a pathophysiological perspective NOACs can be used in these patients. ${ }^{17,18}$

\section{Practical start-up and follow-up scheme for patients on non-vita- min $\mathrm{K}$ antagonist oral anticoagulants}

With four NOACs available in different dosages for different indications and with different dose-reduction criteria, identification of the correct dose has become more complicated and is one of the key challenges in the daily use and individualization of treatment. ${ }^{19-23}$ Dose reduction of NOACs is primarily recommended only according to the dose-reduction criteria investigated in the large phase III trials. Whenever possible, the tested standard dose of NOACs should be used. Also, patient age, weight, renal function, co-medications, and other comorbidities influence the choice.

Bleeding risk should be systematically assessed, e.g. by the HASBLED or other bleeding risk scores. ${ }^{24,25}$ Importantly, however, a high bleeding risk in itself should not automatically result in decision not to anticoagulate as stroke risk tracks along with the bleeding risk. 5,26 For the practical management, correcting and minimizing modifiable risk factors is of critical importance in order to minimize the risk of bleeding while on treatment with a NOAC. ${ }^{5}$

The proposed NOAC card (Figure 1) presented in this version of the Practical Guide has been updated and will be available for download in various languages at www.NOACforAF.eu. Critical elements in the follow-up of patients (and in the assurance of optimal adherence) are summarized in Figure 2.

\section{Importance of drug-drug interactions of non-vitamin $\mathrm{K}$ antagonist oral anticoagulants}

Despite fewer interactions with NOACs compared to VKA, physicians need to consider the pharmacokinetic interactions of accompanying drugs and comorbidities when prescribing NOACs. ${ }^{2}$ The use of plasma level monitoring for NOAC dose-adjustment is discouraged for the vast majority of patients due to the lack of outcome data 


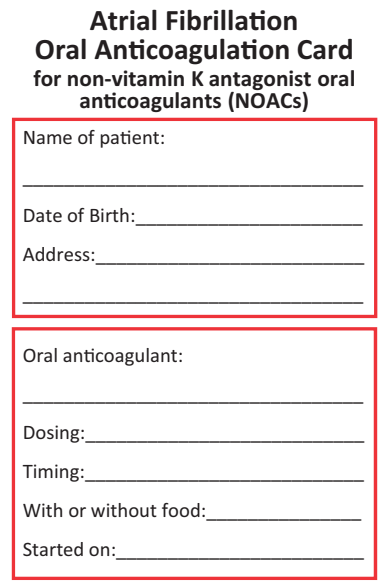

Page 1

Information for healthcare providers

\begin{tabular}{|l|}
\hline - NOACs act as a direct thrombin inhibitor \\
(dabigatran) or direct factor Xa inhibitor \\
(apixaban, edoxaban, rivaroxaban). \\
- Check contraindications for NOACs: mechanical \\
heart valve; rheumatic mitral stenosis; severe \\
kidney dysfunction. \\
- Standard tests (such as INR, PT or aPTT) do not \\
quantitatively reflect level of anticoagulation. \\
- In case ef major bleeding events, NOAC should be \\
stoped immediately. \\
- For certain procedures, NOAC should be stopped \\
in advance (for timing see NOAC Practical Guide). \\
\hline
\end{tabular}

Recommended follow-up

\section{Check each visit:}

1. Adherence (pt. should bring remaining meds)

2. Thromboembolic event

3. Bleeding events

4. Other side effects

5. Co-medications / over-the-counter drugs

6. Need for blood samplin

8. Optimal NOAC and correct dosing

(see wWw.NOACforAF.eu for more information)

Page 5

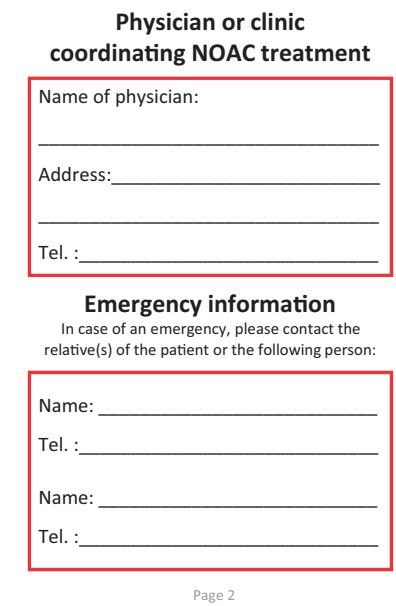

Information for healthcare providers

Blood sampling follow-up
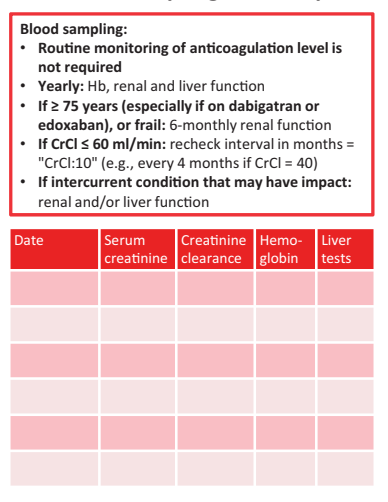

Important patient instructions

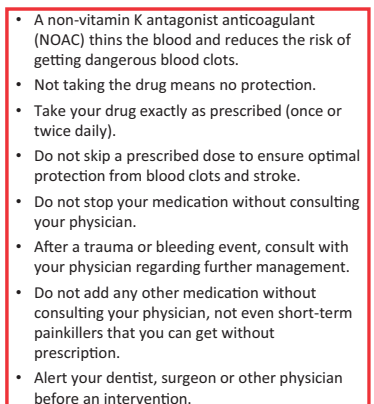

- Alert your den

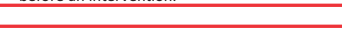

It is important to carry this card with you at all times. Please show this card to every

physician, dentist, pharmacist or other healthcare providers.

Page 3

Planned or unplanned visits
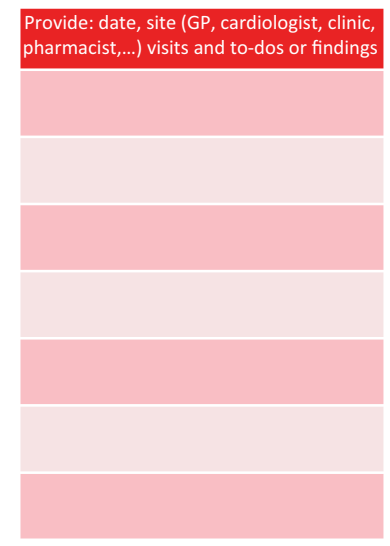

Page 7
What to do in certain occasions

When should I contact a healthcare provider? Bleeding is the most common side effect of an anticoagulant. However, the reduction in the risk for stroke outweighs the bleeding risk. Contact your healthcare provider if you have any signs or symptoms of bleeding such as: - Unusual bruising, nosebleeds, bleeding of gums, bleeding from cuts that take a long time to stop

Menstrual flow or vaginal bleeding that is

heavier than normal

Blood in urine, red or black stools

- Coughing up blood or vomiting blood

- Dizziness, paleness or weakness

What should I do if I missed a dose?

You should still take that dose, unless the time until your next dose is less than the time after your missed dose.

What if I accidently took two doses?

- Twice daily NOAC: you can opt to forgo the next planned dose and restart after $24 \mathrm{~h}$.

Once daily NOAC: you can continue the

normal regimen without skipping a dose.

\section{Page 4}

Concomitant medication

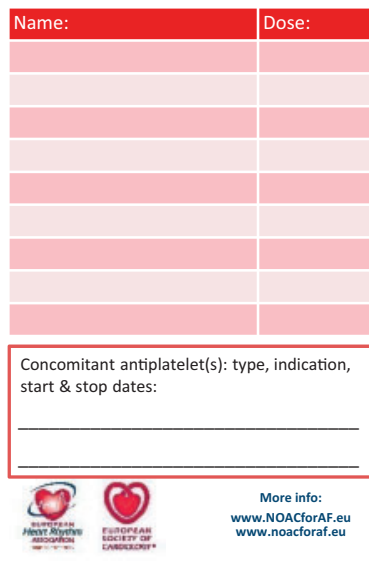

Page 8

Figure I The EHRA NOAC card, which can be folded into a pocket size. A patient information card is crucial, both for the patient (instructions on correct intake; contact information in case of questions) as for healthcare providers. This generic and universal card can serve all patients under NOAC therapy. aPTT, activated partial thromboplastin time; $\mathrm{CrCl}$, creatinine clearance; EHRA, European Heart Rhythm Association; GP, general practitioner; Hb, hemoglobin; INR, international normalized ratio; NOAC, non-vitamin K antagonist oral anticoagulant; PT, prothrombin time.

to support such an approach. Only in very rare cases of potentially substantial drug-drug interactions or special situations in which a certain NOAC is preferred for certain reasons (e.g. patients after transplantation, patients on HIV medication etc.) this may be considered. Importantly, this approach should be limited to centres with extensive experience in the performance and interpretation of such assays as well as in the care of NOAC-treated patients.

\section{Non-vitamin K antagonist oral anticoagulants in patients with chronic kidney disease or advanced liver disease}

In the context of NOAC treatment, renal function should preferably be estimated by calculating the creatinine clearance $(\mathrm{CrCl})$ using the Cockcroft-Gault method, which was used in most NOAC trials. In patients on NOACs, renal function needs to be monitored diligently, at least yearly, to detect changes in renal function and adapt the dose accordingly. If renal function is impaired (i.e. $\mathrm{CrCl} \leq 60 \mathrm{~mL} / \mathrm{min}$ ), a more frequent evaluation is recommended (e.g. by dividing $\mathrm{CrCl}$ by 10 to obtain the minimum frequency of renal function testing in months).

Compared with warfarin, all four NOACs showed consistent efficacy and safety in patients with mild to moderate chronic kidney disease (CKD) compared with non-CKD patients in the respective subgroup analyses of pivotal NOAC trials. ${ }^{27-32}$ In addition, the ARISTOTLE trial data analysis suggests that the bleeding benefit with apixaban compared to warfarin becomes significantly more prominent at lower $\mathrm{CrCl}$ values, while the stroke reduction benefit is maintained. $^{29-33}$ In contrast, the bleeding benefit of $110 \mathrm{mg}$ dabigatran over warfarin is lost in patients with $\mathrm{CrCl}<50 \mathrm{~mL} / \mathrm{min}$ while maintaining a similar stroke risk reduction compared to VKA. ${ }^{27}$

There are no randomized clinical trial (RCT) data on the use of NOACs or warfarin for stroke prevention in AF patients with 


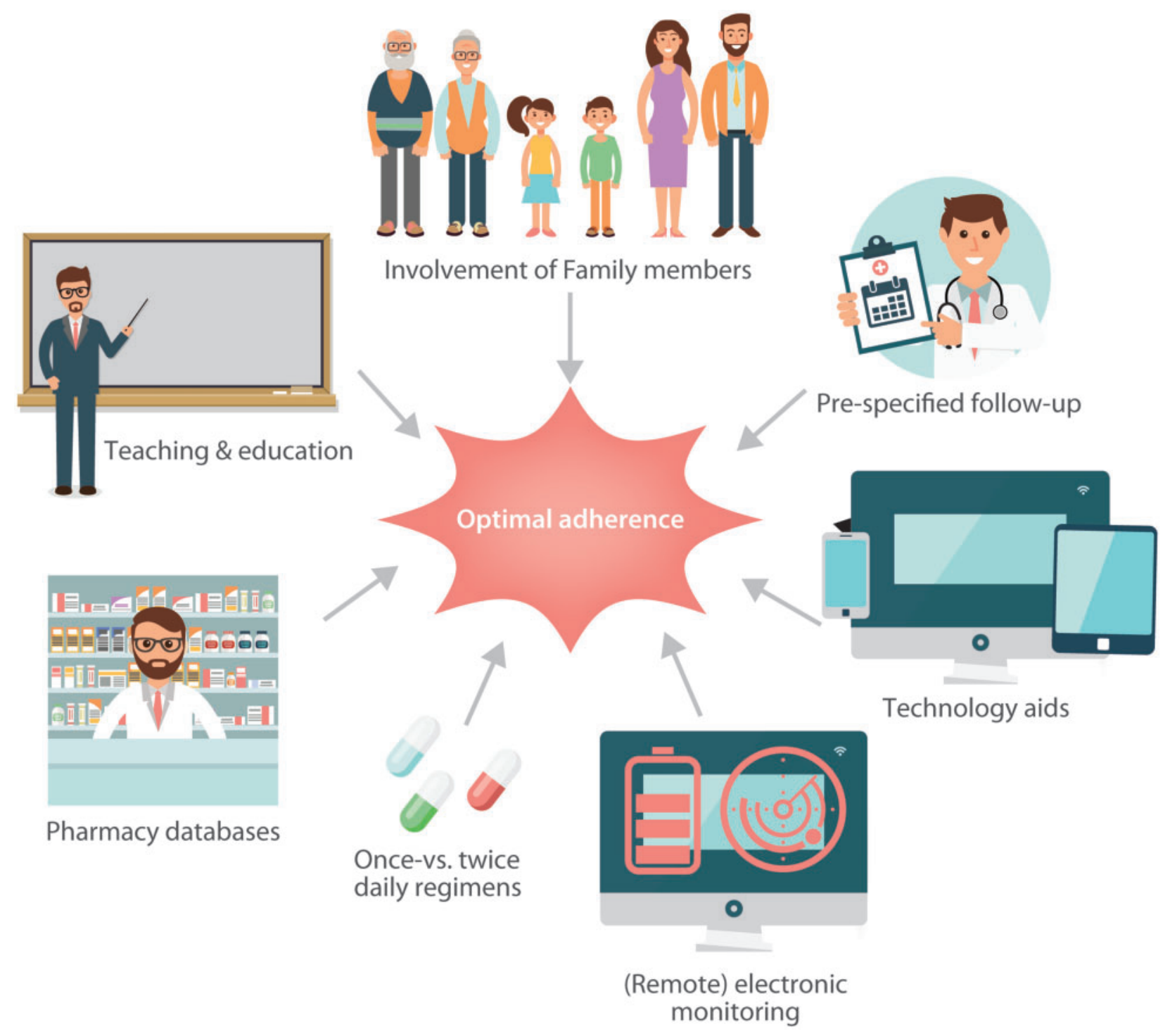

Figure 2 Selection of possibilities to increase adherence to NOACs. NOAC, non-vitamin K antagonist oral anticoagulant.

severe CKD or on renal replacement therapy (RRT). The efficacy and safety of NOACs in patients with end-stage renal dysfunction and on dialysis is unclear and subject to ongoing studies (e.g. NCT02942407 and NCT02933697). Given the lack of strong evidence also for VKA in this patient population, the decision to anticoagulate remains a very individualized one requiring a multidisciplinary approach considering and respecting patients' preferences. $^{34-36}$

The use of VKAs in patients with advanced liver disease and coagulopathy is challenging due to intrinsically elevated International Normalized Ratio (INR) values and difficulties in selecting appropriate VKA dosing. ${ }^{37-41}$ Also all four NOACs are contraindicated in patients with hepatic disease associated with coagulopathy and clinically relevant bleeding risk including Child-Turcotte-Pugh $C$ cirrhosis. Rivaroxaban should also not be used in AF patients with Child B liver cirrhosis. $^{42}$

\section{How and when to measure the anticoagulant effect of non-vitamin $\mathrm{K}$ antagonist oral anticoagulants?}

Non-vitamin $\mathrm{K}$ antagonist oral anticoagulants do not require monitoring of coagulation. However, laboratory assessment of drug exposure and anticoagulant effect may help clinicians in emergencies such as bleeding, urgent procedures, suspected overdose, or acute stroke. It can also be considered to guide long-term treatment in exceptional patients with special characteristics. This, however, should only be done under the guidance of a coagulation expert and in the knowledge that hard clinical outcome data do not exist for such a strategy.

Routine coagulation tests (PT and aPTT) generally do not provide an accurate assessment of NOAC anticoagulant effects. Conversely, 
the latter can be measured via specific coagulation assays developed for the quantification of NOAC plasma levels. ${ }^{43-45}$ The use of appropriate calibrators allows for the determination of plasma concentrations of all NOACs. It is recommended that labs should be experienced with these measurements. Moreover, emergency situations will require 24/7 availability of the specific assays, which is currently only possible in a minority of labs.

\section{Management of bleeding under non-vitamin $\mathrm{K}$ antagonist oral anticoagulant therapy}

Strategies to manage bleeding complications in patients treated with NOACs rely on a precise analysis of the clinical situation.

(1) The type of bleeding: nuisance/minor, major non-life-threatening, or life-threatening.

(2) The patient and his/her treatment, including the exact time of last NOAC intake, prescribed dosing regimen, renal function, other factors influencing plasma concentrations, and other factors influencing haemostasis (such as concomitant use of antiplatelet drugs).

Depending on the clinical scenario, the anticoagulant effects in a NOAC-treated patient who presents with bleeding can be addressed with the following strategies:

(1) Waiting until the anticoagulant activity of the NOAC effect wanes as a result of spontaneous clearance of the drug.

(2) Specific reversal. A specific reversal agent is available for dabigatran (idarucizumab, a humanized antibody fragment that specifically binds dabigatran). ${ }^{46}$ Specific agents for FXa inhibitors are undergoing clinical testing, including andexanet alfa $^{47}$ and ciraparantag (PER 977). ${ }^{48}$

(3) Non-specific support of haemostasis using coagulation factors concentrates. There is increasing information about the effects of (activated) prothrombin complex concentrates in cohorts of NOAC-treated patients with bleeding. ${ }^{49}$ In contrast, the use of fresh frozen plasma is not considered a useful reversal strategy. ${ }^{50}$ The use of antifibrinolytics (e.g. tranexamic acid, $1 \mathrm{~g}$ i.v., repeated every $6 \mathrm{~h}$ if needed) or desmopressin $0.3 \mu \mathrm{g} / \mathrm{kg}$ i.v. infusion (with a maximal dosing of $20 \mu \mathrm{g}$ ) - especially in special situations with associated coagulopathy or thrombopathy-may be considered.

Nuisance bleeds can usually be managed by delaying intake or withholding the NOAC for a maximum of one dose. Minor bleedings may require more aggressive therapy with a focus aimed at treating the cause of the bleeding (e.g. PPI for gastric ulcers, antibiotics for urinary tract infection, etc.). Epistaxis and gum bleeds can be treated with local anti-fibrinolytics. In case of recurrent minor bleeding events without causal therapeutic options, an alternative NOAC with a potentially different bleeding profile should be considered while maintaining effective stroke prevention. A suspected or documented occult bleeding should trigger a workup to uncover the underlying cause and the treatment thereof whenever possible. Cessation or temporary interruption without consultation needs to be discouraged due to the subsequently increased thromboembolic risk. Major and/or life-threatening bleeding needs to be aggressively managed including the use of specific as well as nonspecific reversal strategies.

\section{Patients undergoing a planned invasive procedure, surgery, or ablation}

Awaiting the results of the ongoing Perioperative Anticoagulant Use for Surgery Evaluation (PAUSE; NCT02228798), few prospective data on the management of NOACs are available. ${ }^{51}$

It is recommended not to interrupt oral anticoagulation for most minor surgical procedures, and those procedures where bleeding is easily controllable. In general, these procedures can be performed 12-24 $\mathrm{h}$ after the last NOAC intake, with NOAC restart $6 \mathrm{~h}$ later.

For invasive procedures with a low bleeding risk (including cardiac device implantations), it is recommended to take the last dose of a NOAC $24 \mathrm{~h}$ before the elective procedure in patients with normal kidney function. ${ }^{52}$ For patients on dabigatran and a $\mathrm{CrCl}<80 \mathrm{~mL} / \mathrm{min}$, a graded interruption should be considered.

In case of invasive procedures that carry a high risk for major bleeding, it is recommended to take the last NOAC dose $48 \mathrm{~h}$ or longer before surgery. In cases with combined factors that make prediction of NOAC clearance unclear, measurement of NOAC plasma levels may be considered, and only go ahead with the planned surgical intervention when the level is considered low enough. However, such an approach is without evidence base, including the determination of 'safe' NOAC levels in this setting as well as waiting for levels to drop into that range whilst accepting the inherent risk of thromboembolism during that time.

Preoperative bridging with low molecular weight heparin $(\mathrm{LMWH})$ or heparin is not recommended in NOAC-treated patients.

After a procedure with immediate and complete haemostasis, NOACs can generally be resumed $6-8 \mathrm{~h}$ after the end of the intervention. In surgical interventions for which resuming full dose anticoagulation within the first $48-72 \mathrm{~h}$ after the procedure carries a bleeding risk that may outweigh the risk of AF-related embolism, initiation of post-operative thromboprophylaxis 6-8 h after surgery and restarting the NOAC $48-72 \mathrm{~h}$ postoperatively, but as soon as possible, can be considered.

Whether opting to administer the last NOAC dose shortly before an AF ablation procedure (i.e. 'truly uninterrupted') or to go for a short cessation period (last NOAC dose on the day before the procedure), may depend on a number of factors (Figure 3). ${ }^{2,53-58}$ It is reasonable to administer a last dose of NOAC $12 \mathrm{~h}$ before the start of the intervention, especially if transseptal puncture is performed without periprocedural imaging (as is mostly the case in Europe). ${ }^{53}$

\section{Patients requiring an urgent surgical intervention}

If an emergency intervention is required, the NOAC should be discontinued immediately. Specific management will then depend on the level or urgency. ${ }^{59}$ 


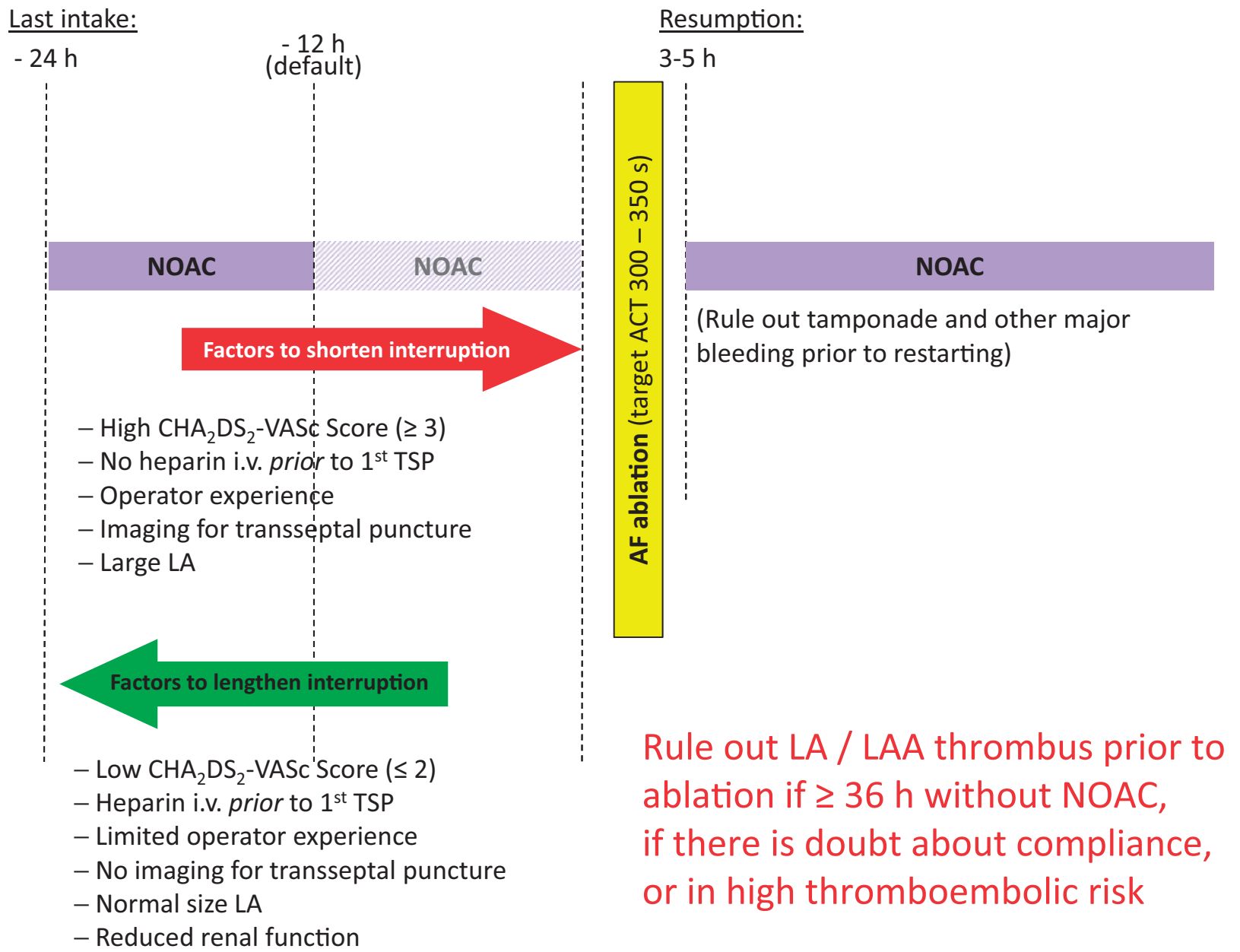

Figure 3 Non-vitamin $\mathrm{K}$ antagonist oral anticoagulant management before and after atrial fibrillation ablation. ACT, activated clotting time; AF, atrial fibrillation; LA, left atrium; LAA, left atrial appendage; NOAC, non-vitamin K antagonist oral anticoagulant; TSP, transseptal puncture.

Immediate procedures (immediate life-, limb-, or organ-saving intervention, typically cardiac, vascular, neurosurgical emergency procedures) need to be performed within minutes of the decision to operate and cannot be delayed. In these cases, reversal with idarucizumab (for dabigatran) ${ }^{46}$ should be considered, especially in moderateto high-haemorrhagic risk procedures. ${ }^{60}$ If specific reversal agents are not available, prothrombin complex concentrate (PCC) or activated PCC (aPCC) should be considered despite the clinical lack of evidence for efficacy and safety (only animal data). ${ }^{61-63}$

Urgent procedures (e.g. intervention for acute onset or clinical deterioration of potentially life-threatening conditions, conditions that may threaten the survival of limb or organ, fixation of fractures, relief of pain, or other distressing symptoms) need to be performed within hours of the decision to operate. In these situations, surgery or intervention should be deferred, if possible, until at least $12 \mathrm{~h}$ and ideally $24 \mathrm{~h}$ after the last dose. Also, coagulation test results (see below) can be awaited in this situation to gauge the necessity for reversal or application of (a)PCCs.

Expedite procedures (patients requiring early treatment where the condition is not an immediate threat to life, limb, or organ survival) should be performed within days of decision to operate. In these situations, interruption of NOACs should follow the proposed rules for elective surgery.

\section{Patient with atrial fibrillation and coronary artery disease}

The combination of AF and coronary artery disease is not only a common and complex clinical setting to deal with regarding anticoagulation and antiplatelet therapy, it is also associated with significantly higher morbidity and mortality. ${ }^{64,65}$ The practice of adding aspirin or a P2Y 12 inhibitor to a (N)OAC is referred to as 'dual therapy', while adding both aspirin and a P2Y 12 inhibitor to a (N)OAC is called 'triple therapy'. Dual antiplatelet therapy is referred to as 'DAPT'.

Recent randomized clinical trials (WOEST, PIONEER AF, RE-DUAL $\mathrm{PCl}$ ) have revealed an almost halved risk for clinically relevant bleeding in patients with AF treated with dual therapy compared to triple therapy after $\mathrm{PCl}$. Albeit those studies were individually underpowered for efficacy, a meta-analysis suggests that the likelihood of an excess of 
thrombo-embolic events during dual therapy vs. triple therapy is low. ${ }^{66}$ Two ongoing trials, AUGUSTUS (NCT02415400) and ENTRUST-AF $\mathrm{PCl}(\mathrm{NCT} 02866175)^{67}$ will add further information on how and how long (if at all) triple anticoagulation should be administered.

In general, the bleeding risk seems to be lower with a NOAC plus antiplatelet combination than with a VKA plus antiplatelet combination. $^{68-70}$ The length of DAPT/triple therapy no longer depends on the type of stent [i.e. Drug-eluting stent (DES) or bare metal stent (BMS)] but on the clinical presentation of the patient. ${ }^{5,71}$ Today, the 'default' duration of triple therapy may be as short as 3 months after ACS and 1 month after elective stenting; however, both the duration of aspirin and/or P2Y 12 inhibitor as well as the choice of NOAC need to be individualized, based on a careful assessment of ischaemic- vs. bleeding risk. In the setting of dual therapy it may be feasible to use one of the newer P2Y 12 inhibitors with a (N)OAC under certain circumstances such as perceived high-thrombotic risk, ACS, or prior stent thrombosis.

The 2017 ESC DAPT and 2016 AF guidelines recommend discontinuing any antiplatelet agent at 12 months after a PCl or ACS and to only consider keeping one antiplatelet plus a (N)OAC beyond 12 months in patients at very high risk of coronary events. ${ }^{5,71}$

\section{Cardioversion in a non-vitamin $\mathrm{K}$ antagonist oral anticoagulant treated patient}

Based on current ESC guidelines, ${ }^{5}$ in patients with AF of $\geq 48 \mathrm{~h}$ (or unknown) duration undergoing electrical or pharmacological cardioversion, effective oral anticoagulation needs to be established for at least 3 weeks prior to cardioversion or transoesophageal echocardiography (TOE) performed to rule out left atrial thrombi. After cardioversion, continuous oral anticoagulation is mandatory for at least another 4 weeks, irrespective of $\mathrm{CHA}_{2} \mathrm{DS}_{2}$-VASc score., ${ }^{5,72}$

A strategy with at least a single NOAC dose $\geq 4 \mathrm{~h}$ before cardioversion ( $\geq 2 \mathrm{~h}$ after apixaban loading dose) appears safe and effective in patients with $\mathrm{AF}$ of $\geq 48 \mathrm{~h}$ duration, provided that a TOE is performed prior to cardioversion. The alternative is starting anticoagulation with a NOAC first, and delaying cardioversion for at least 3 weeks. ${ }^{73-77}$ A similar strategy of starting the NOAC before cardioversion, with a TOE dependent on institutional policy or patient-elevated stroke risk, is applicable to those with AF of $<48 \mathrm{~h}$ duration.

Patients in whom TOE identifies a left atrial thrombus should not undergo cardioversion. Treatment with VKA is standard in these situations but NOACs may also be an option, particularly in patients where a VKA is not well tolerated or adequate INR control cannot be obtained.

\section{Atrial fibrillation patients presenting with acute stroke while on non-vitamin $\mathrm{K}$ antagonist oral anticoagulant}

According to current guidelines and official labelling, thrombolytic therapy with recombinant tissue plasminogen activator (rt-PA) is approved within $4.5 \mathrm{~h}$ of onset of stroke symptoms but should not be administered in patients on full anticoagulation. Therefore, thrombolytic therapy cannot be given within $24 \mathrm{~h}$ after the last intake of a NOAC due to their plasma half-lives. The case is different for dabigatran due to the availability of the rapid acting specific reversal agent, idarucizumab. After reversal and assessment of coagulation status, intravenous thrombolysis within $4.5 \mathrm{~h}$ of onset of moderate to severe stroke seems feasible and safe according to case series. ${ }^{78-80}$ Based on expert consensus, the use of rt-PA may be considered in selected patients on a NOAC in cases in which a reliable and NOAC specific coagulation assessment is available without long delay and demonstrating a concentration $<30 \mathrm{ng} / \mathrm{mL}$ for rivaroxaban, apixaban, or edoxaban (see main document for detailed discussion). ${ }^{81,82}$

There is a proven benefit of endovascular thrombectomy up to $7.3 \mathrm{~h}$ after stroke onset in selected non-anticoagulated patients with a distal occlusion of the internal carotid artery or the proximal middle cerebral artery, ${ }^{83}$ and thrombectomy also seems to be beneficial in highly selected stroke patients within $6-24 \mathrm{~h}$ of last seen normal. ${ }^{84,85}$ Endovascular thrombectomy is now mentioned as 'first-line treatment' in patients with contraindication for intravenous thrombolysis, while the AHA guidelines provide no specific recommendation in this regard. ${ }^{86,87}$ Although the trials underlying these recommendations either excluded or contained just a few patients on VKA or NOAC, the small amount of data available suggests that endovascular thrombectomy may be safe also in these individuals but an impact of present anticoagulation on reperfusion-related bleeding risk has to be taken into account. ${ }^{88}$

In AF patients after ischaemic stroke, NOACs should be (re-) initiated in analogy to clinical practice with VKAs. Recommendations on (re-) starting of oral anticoagulation after ischaemic stroke must outweigh (recurrent) stroke risk vs. secondary haemorrhagic transformation. ${ }^{5,89-91}$

In analogy to patients with acute intracranial bleeding (ICB) being treated with warfarin, discontinuation of the drug, urgent blood pressure management, and rapid correction of the coagulation status (ideally with a direct reversal agent) is needed to limit haematoma enlargement in patients under NOACs. ${ }^{92-94}$

In the absence of randomized controlled trials, a case-by-case consideration is needed whether or not to reintroduce anticoagulation of any type in patients who have experienced an anticoagulationrelated ICB. ${ }^{5,94-96}$ Left atrial appendage occlusion may be considered, but also here randomized evidence is missing, which is why, ideally, treatment should occur in the framework of a randomized trial to contribute to evidence. $^{97}$

\section{Non-vitamin K antagonist oral anticoagulants in special situations}

Meta-analyses of NOAC trial data suggest no interaction of age for safety and efficacy (except for an increased risk of extracranial bleeding in patients $\geq 75$ vs $<75$ years with both doses of dabigatran as compared to Warfarin). ${ }^{98,99}$ Importantly, the higher absolute stroke risk resulted in a larger absolute risk reduction by using NOACs instead of VKA in these older patients, resulting in a lower number needed to treat compared to younger patients (see Table 1). ${ }^{100}$ 
Table I Summary of age profile and interaction of age on bleeding in NOAC trials

\begin{tabular}{|c|c|c|c|}
\hline \multirow[t]{2}{*}{ Trial } & \multirow{2}{*}{$\begin{array}{l}\geq 75 \text { subgroup } \\
\text { overall \% (number } \\
\text { of patients) }\end{array}$} & Major bleeding & Intracranial bleeding \\
\hline & & \multicolumn{2}{|c|}{ (\%/pt years NOAC vs VKA per age group $P$ interaction for age) } \\
\hline RE-LY & $41 \%(n=7258)$ & & \\
\hline \multirow[t]{3}{*}{ 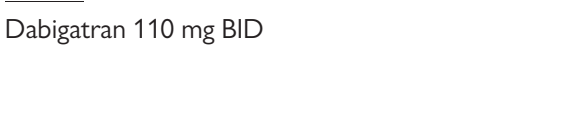 } & & $\geq 75: 4.43 \%$ vs. $4.37 \%$ & $\geq 75: 0.37 \%$ vs $1.00 \%$ \\
\hline & & $<75: 1.89 \%$ vs $3.04 \%$ & $<75: 0.14 \%$ vs $0.61 \%$ \\
\hline & & $P$ for interaction $<0.001$ & $P$ for interaction $=0.28$ \\
\hline \multirow[t]{3}{*}{ Dabigatran 150 mg BID } & & $\geq 75: 5.10 \%$ vs $4.37 \%$ & $\geq 75: 0.41 \%$ vs $1.0 \%$ \\
\hline & & $<75: 2.12 \%$ vs $3.04 \%$ & $<75: 0.26 \%$ vs $0.61 \%$ \\
\hline & & $P$ for interaction $<0.001$ & $P$ for interaction $=0.91$ \\
\hline ROCKET-AF & $44 \%(n=6229)$ & & \\
\hline Rivaroxaban $20 \mathrm{mg}$ OD (per protocol dose & & $\geq 75: 4.86 \%$ vs $4.40 \%$ & $\geq 75: 0.34 \%$ vs $0.49 \%$ \\
\hline \multirow[t]{2}{*}{ reduction to $15 \mathrm{mg}$ in $20 \%)$} & & $<75: 2.69 \%$ vs $2.79 \%$ & $<75: 0.20 \%$ vs $0.41 \%$ \\
\hline & & $P$ for interaction $=0.336$ & $P$ for interaction $=0.365$ \\
\hline ARISTOTLE & $31 \%(n=5678)$ & & \\
\hline Apixaban $5 \mathrm{mg}$ BID(per protocol dose reduction to & & $\geq 75: 3.3 \%$ vs $5.2 \%$ & $\geq 75: 0.43$ vs $\% 1.29 \%$ \\
\hline \multirow[t]{3}{*}{$2.5 \mathrm{mg}$ BID in $4.7 \%)$} & & $65-74: 2.0 \%$ vs $2.8 \%$ & $65-74: 0.28 \%$ vs $0.81 \%$ \\
\hline & & $<65: 1.17 \%$ vs $1.51 \%$ & $<65: 0.31 \%$ vs $0.35 \%$ \\
\hline & & $P$ for interaction $=0.63$ (continuous) & $P$ for interaction $=0.20$ (continuous) \\
\hline ENGAGE-AF TIMI 48 & $40 \%(n=8474)$ & & \\
\hline Higher dose edoxaban regimen & & $\geq 75: 4.0 \%$ vs $4.8 \%$ & $\geq 75: 0.5 \%$ vs $1.2 \%$ \\
\hline Edoxaban $60 \mathrm{mg}$ OD $(28.6 \%<75$ and $41 \% \geq 75$ & & $<75: 2.0 \%$ vs $2.6 \%$ & $<75: 0.3 \%$ vs $0.6 \%$ \\
\hline dose reduced to $30 \mathrm{mg}$ ) & & $P$ for interaction $=0.57$ & $P$ for interaction $=0.34$ \\
\hline Lower dose edoxaban regimen* & & $\geq 75: 2.3 \%$ vs $4.8 \%$ & $\geq 75: 0.4 \%$ vs $1.2 \%$ \\
\hline Edoxaban $30 \mathrm{mg}$ OD $(28.6 \%<75$ and $41 \% \geq 75$ & & $<75: 1.2 \%$ vs $2.6 \%$ & $<75: 0.2 \%$ vs $0.6 \%$ \\
\hline dose reduced to $15 \mathrm{mg}$ ) & & $P$ for interaction $=0.95$ & $P$ for interaction $=0.99$ \\
\hline
\end{tabular}

*Not licensed.

Falls and risk of subdural haemorrhage in particular are often considered by physicians as a contraindication to OAC. ${ }^{101,102}$ However, frailty and a (perceived) increased risk of falling per se should not be an exclusion criterion to anticoagulate since frail and older patients are at an increased risk of stroke and have been shown to benefit from NOAC therapy (best shown for edoxaban and apixaban). ${ }^{103-108}$

Dementia should not be a viewed as a general contraindication to anticoagulation either, especially if well managed from a logistical point of view. Paradoxically, the fact that others take care of providing medication to dementia patients may guarantee higher adherence.

Overall, NOACs appear to be similarly safe and effective in patients with moderate obesity (up to $120 \mathrm{~kg}$ ) or moderate underweight (down to $50 \mathrm{~kg}$ ). ${ }^{41,109-123}$ For patients with low body weight (<60 kg) specific dose-reduction criteria were employed in the trials for edoxaban and apixaban possibly making those drugs the preferred choice in these patients. Because of limited data in extremes of body weight, the use of VKA in patients with a body mass index $\geq 40 \mathrm{~kg} / \mathrm{m}^{2}$ (or weight $>120 \mathrm{~kg}$ ) as well as in those weighting $<50 \mathrm{~kg}$ should be considered (in line with recommendations from the International Society on Thrombosis and Haemostasis). ${ }^{116}$ In rare case when a NOAC is needed in such circumstances, specific measurements of drug trough levels should be considered. This, however, should only be done under the guidance of a coagulation expert and in the knowledge that hard clinical outcome data do not exist for such an approach.

All OAC use should be considered with caution in women of childbearing age and an appropriate test to rule out pregnancy and contraceptive counselling advice arranged before initiation of any agent. Abnormal uterine bleeding (AUB; formerly called menorrhagia), occurs in $9-14 \%$ of the general female population of reproductive age, ${ }^{124}$ which may be exacerbated by oral anticoagulants. ${ }^{125}$ All cases of AUB on OAC need to have gynaecological assessment. Importantly, NOACs are contraindicated in pregnancy as well as during breastfeeding.

In patients with epilepsy, anticoagulation is affected by antiepileptic drugs via various potential interactions. ${ }^{126}$ The significance of these drug-drug interactions is still largely unknown with only occasional case reports available.

\section{Anticoagulation in atrial fibrillation patients with a malignancy}

So far, the only published RCT specifically targeting cancer patients stems from the HOKUSAI-VTE Cancer trial comparing edoxaban 
with LMWH in patients with VTE (but not AF). ${ }^{127}$ In line with these findings, several meta-analyses of the small subgroup of cancer patients in VTE trials reported similar or better efficacy of NOACs in comparison to VKA or LMWH for VTE prevention, although major bleeding rates were higher. ${ }^{128,129}$ In how far these findings apply to AF patients with cancer requires further data. Indeed, much is still unknown about drug-drug interactions between NOACs and specific chemotherapeutic agents, urging further caution. ${ }^{130}$

\section{Optimizing dose adjustments of vitamin $\mathrm{K}$ antagonists}

Automated dosing calculators are available that help in the determination of the 'optimal' starting regimen for VKA (e.g. http://www.war farindosing.org). During maintenance therapy, using dosing algorithms to optimize VKA dosing and, ultimately, the time in therapeutic range (TTR) has been shown to be useful. ${ }^{131-133}$ Importantly from a conceptual point of view, dosing is optimized not using daily dose adjustments but adjustments based on the weekly intake in warfarin. Receiving care at a dedicated anticoagulation clinic ${ }^{134,135}$ as well as self-monitoring and self-management ${ }^{136}$ has been shown to improve INR control in well-selected patients.

\section{Acknowledgements}

EHRA Scienfitic Documents committee: Gregory Y. H. Lip, Laurent Fauchier, David Arnar, Carina Blomstrom-Lundqvist, Zbigniew Kalarus, Gulmira Kudaiberdieva, Georges H Mairesse, Tatjana Potpara, Irina Savelieva, Jesper Hastrup Svendsen, and Vassil B. Traykov.

Conflict of interest: J.S. has received consultant and/or speaker fees from Amgen, Astra-Zeneca, Atricure, Bayer, Biosense Webster, Biotronik, Boehringer-Ingelheim, Boston Scientific, Bristol-Myers Squibb, Cook Medical, Daiichi Sankyo, Medtronic, Novartis, Pfizer, Sanofi-Aventis, Sorin, St. Jude Medical/Abbott and Zoll. He reports ownership of CorXL. He has received grant support through his institution from Bayer Healthcare, Biosense Webster, Biotronik, Boston Scientific, Daiichi Sankyo, Medtronic, und St. Jude Medical/ Abbott. P.V. reports grants and personal fees from Bayer, Boehringer Ingelheim, BMS, Leo Pharma, Daiichi-Sankyo; and personal fees from Pfizer, Medtronic, and Portola. T.S.P. has received speaker fees from Pfizer and Bayer. P.A. reports personal fees from Boehringer Ingelheim, personal fees and non-financial support from Bayer and Portola, and grants, personal fees and non-financial support from Pfizer-BMS and Csl-Behring. M.A. reports personal fees from Bayer, Boehringer Ingelheim, Daiichi Sankyo, personal fees from Pfizer, Sanofi Aventis, Medtronic, Biosense Webster, Novartis, Abbott, and Biotronik. L.D. has no conflict of interest to disclose. K.G.H. reports personal fees from Bayer, Boehringer-Ingelheim, Pfizer, Bristol-Myers Squibb, Daiichi Sankyo, Medtronic, Edwards Lifesciences, Sanofi, EIP Pharma, non-financial support from Getemed AG, and grants from Bayer. J.O. reports fees to his institution from Bayer, Boehringer Ingelheim, Bristol-Myers Squibb, Daichii-Sankyo, Pfizer, and Sanofi. H.R. reports personal fees from BMS, MedUpdate, NephroUpdate, Pfizer, and Pluristem; and grants from the German Federal Ministry for Education and Research (BMBF), Bard, Bayer, and
Biotronik. V.R.-S. has received consultant and/or speaker fees from Bayer Healthcare, Boehringer-Ingelheim, Bristol-Myers Squibb, Leo Pharma, Pfizer, and Rovi. N.R.: reports personal fees from BMS, Pfizer, Daiichi-Sankyo, Bayer, and Boehringer Ingelheim. P. S.: reports grants from Daiichi Sankyo and Astra Zeneca, and institutional fees from BMS, Pfizer, and Boehringer. R.C. reports personal fees from Daichii Sankyo, Pfizer, Bayer, and Boehringer Ingelheim. J.C. has received institutional research grants and personal fees for advice and for speaking from Bayer, Boehringer Ingelheim, Daiichi Sankyo, and Pfizer/BMS. H.H. reports personal fees before June 2017 from Abbott, Pfizer/BMS, Daiichi-Sankyo, Boehringer-Ingelheim, Cardiome; he received no personal fees after June 2017; he received research grants from Bayer, Bracco Imaging Europe, Medtronic, and St. Jude Medical through the Universities of Hasselt and Antwerp, Belgium.

\section{Funding}

This article and derived educational materials (slide set, website, booklet, and NOAC card) were produced by and under the sole responsibility of the European Heart Rhythm Association, and supported by Bayer Pharma AG, Boehringer Ingelheim, Bristol-Myers Squibb, and Pfizer Alliance and Daiichi-Sankyo Europe $\mathrm{GmbH}$ in the form of an Unrestricted Educational Grant. The EHRA writing committee collaborated with medical advisors from the different companies to assure data accuracy and completeness.

\section{References}

1. Heidbuchel H, Verhamme P, Alings M, Antz M, Diener HC, Hacke W et al. Updated European Heart Rhythm Association Practical Guide on the use of non-vitamin $\mathrm{K}$ antagonist anticoagulants in patients with non-valvular atrial fibrillation. Europace 2015;17:1467-507.

2. Heidbuchel H, Verhamme P, Alings M, Antz M, Hacke W, Oldgren J et al.; European Heart Rhythm Association. European Heart Rhythm Association Practical Guide on the use of new oral anticoagulants in patients with nonvalvular atrial fibrillation. Europace 2013;15:625-51.

3. Kotecha D, Breithardt G, Camm AJ, Lip GYH, Schotten U, Ahlsson A et al. Integrating new approaches to atrial fibrillation management: the 6th AFNET/ EHRA Consensus Conference. Europace 2018;20:395.

4. Steffel J, Verhamme P, Potpara TS, Albaladejo P, Antz M, Desteghe L et al. The 2018 European Heart Rhythm Association Practical Guide on the use of nonvitamin $\mathrm{K}$ antagonist oral anticoagulants in patients with atrial fibrillation. Eur Heart J 2018. doi:10.1093/eurheartj/ehy136.

5. Kirchhof P, Benussi S, Kotecha D, Ahlsson A, Atar D, Casadei B et al. 2016 ESC Guidelines for the management of atrial fibrillation developed in collaboration with EACTS. Eur Heart J 2016;37:2893-962.

6. Baumgartner H, Falk V, Bax JJ, De Bonis M, Hamm C, Holm PJ et al.; ESC Scientific Document Group. 2017 ESC/EACTS Guidelines for the management of valvular heart disease. Eur Heart J 2017;38:2739-91.

7. Lip GYH, Collet JP, Caterina R, Fauchier L, Lane DA, Larsen TB et al.; ESC Scientific Document Group. Antithrombotic therapy in atrial fibrillation associated with valvular heart disease: a joint consensus document from the European Heart Rhythm Association (EHRA) and European Society of Cardiology Working Group on Thrombosis, endorsed by the ESC Working Group on Valvular Heart Disease, Cardiac Arrhythmia Society of Southern Africa (CASSA), Heart Rhythm Society (HRS), Asia Pacific Heart Rhythm Society (APHRS), South African Heart (SA Heart) Association and Sociedad Latinoamericana de Estimulacion Cardiaca y Electrofisiologia (SOLEACE). Europace 2017;19:1757-8.

8. De Caterina R, John Camm A. Non-vitamin K antagonist oral anticoagulants in atrial fibrillation accompanying mitral stenosis: the concept for a trial. Europace 2016;18:6-11

9. Steffel J, Atar D. Non-vitamin K oral anticoagulants in 'valvular' atrial fibrillation: a call for action. Europace 2016;18:1-3.

10. Avezum A, Lopes RD, Schulte PJ, Lanas F, Gersh BJ, Hanna M et al. Apixaban in comparison with warfarin in patients with atrial fibrillation and valvular heart disease: findings from the Apixaban for Reduction in Stroke and Other Thromboembolic Events in Atrial Fibrillation (ARISTOTLE) trial. Circulation 2015;132:624-32. 
11. Ezekowitz MD, Nagarakanti R, Noack H, Brueckmann M, Litherland C, Jacobs $M$ et al. Comparison of dabigatran and warfarin in patients with atrial fibrillation and valvular heart disease: the RE-LY Trial (Randomized Evaluation of LongTerm Anticoagulant Therapy). Circulation 2016;134:589-98.

12. Breithardt G, Baumgartner H, Berkowitz SD, Hellkamp AS, Piccini JP, Stevens SR et al.; ROCKET AF Steering Committee \& Investigators. Clinical characteristics and outcomes with rivaroxaban vs. warfarin in patients with non-valvular atrial fibrillation but underlying native mitral and aortic valve disease participating in the ROCKET AF trial. Eur Heart J 2014;35:3377-85.

13. De Caterina R, Renda G, Carnicelli AP, Nordio F, Trevisan M, Mercuri MF et al. Valvular heart disease patients on edoxaban or warfarin in the ENGAGE AFTIMI 48 trial. J Am Coll Cardiol 2017;69:1372-82.

14. Pan KL, Singer DE, Ovbiagele B, Wu YL, Ahmed MA, Lee M. Effects of nonvitamin $\mathrm{K}$ antagonist oral anticoagulants versus warfarin in patients with atrial fibrillation and valvular heart disease: a systematic review and meta-analysis. J Am Heart Assoc 2017;6:e005835.

15. Renda G, Ricci F, Giugliano RP, De Caterina R. Non-vitamin K antagonist oral anticoagulants in patients with atrial fibrillation and valvular heart disease. J Am Coll Cardiol 2017;69:1363-71.

16. Noseworthy PA, Yao X, Shah ND, Gersh BJ. Comparative effectiveness and safety of non-vitamin $\mathrm{K}$ antagonist oral anticoagulants versus warfarin in patients with atrial fibrillation and valvular heart disease. Int J Cardiol 2016;209:181-3.

17. Noseworthy PA, Yao X, Shah ND, Gersh BJ. Stroke and bleeding risks in NOAC- and warfarin-treated patients with hypertrophic cardiomyopathy and atrial fibrillation. J Am Coll Cardiol 2016;67:3020-1.

18. Dominguez F, Climent V, Zorio E, Ripoll-Vera T, Salazar-Mendiguchia J, GarciaPinilla JM et al. Direct oral anticoagulants in patients with hypertrophic cardiomyopathy and atrial fibrillation. Int J Cardiol 2017;248:232-8.

19. Ruiz Ortiz M, Muniz J, Rana Miguez P, Roldan I, Marin F, Esteve-Pastor MA, Cequier A, Martinez-Selles $M$ et al. Inappropriate doses of direct oral anticoagulants in real-world clinical practice: prevalence and associated factors. A subanalysis of the FANTASIIA Registry. Europace 2017.

20. Camm AJ, Fox KAA, Peterson E. Challenges in comparing the non-vitamin $\mathrm{K}$ antagonist oral anticoagulants for atrial fibrillation-related stroke prevention. Europace 2018;20:1-11.

21. Huisman MV, Ma CS, Diener HC, Dubner SJ, Halperin JL, Rothman KJ et al.; GLORIA-AF Investigators. Antithrombotic therapy use in patients with atrial fibrillation before the era of non-vitamin $\mathrm{K}$ antagonist oral anticoagulants: the Global Registry on Long-Term Oral Antithrombotic Treatment in Patients with Atrial Fibrillation (GLORIA-AF) Phase I cohort. Europace 2016;18:1308-18.

22. Fosbol EL, Vinding NE, Lamberts M, Staerk L, Gundlund A, Gadsboll K et al. Shifting to a non-vitamin $\mathrm{K}$ antagonist oral anticoagulation agent from vitamin $\mathrm{K}$ antagonist in atrial fibrillation. Europace 2017. doi: 10.1093/europace/eux193. [EPUB ahead of print: 28 June 2017].

23. Heidbuchel $H$, Vrijens B. Non-vitamin $K$ antagonist oral anticoagulants (NOAC): considerations on once- vs. twice-daily regimens and their potential impact on medication adherence. Europace 2015;17:1317-8.

24. Hijazi Z, Oldgren J, Lindbäck J, Alexander JH, Connolly SJ, Eikelboom JW et al.; ARISTOTLE and RE-LY Investigators. The novel biomarker-based ABC (age, biomarkers, clinical history)-bleeding risk score for patients with atrial fibrillation: a derivation and validation study. Lancet 2016;387:2302-11.

25. O'Brien EC, Simon DN, Thomas LE, Hylek EM, Gersh BJ, Ansell JE et al. The ORBIT bleeding score: a simple bedside score to assess bleeding risk in atrial fibrillation. Eur Heart J 2015;36:3258-64.

26. Lip GY, Lane DA. Bleeding risk assessment in atrial fibrillation: observations on the use and misuse of bleeding risk scores. J Thromb Haemost 2016;14:1711-4.

27. Hijazi Z, Hohnloser SH, Oldgren J, Andersson U, Connolly SJ, Eikelboom JW et al. Efficacy and safety of dabigatran compared with warfarin in relation to baseline renal function in patients with atrial fibrillation: a RE-LY (Randomized Evaluation of Long-term Anticoagulation Therapy) trial analysis. Circulation 2014; 129:961-70

28. Fox KA, Piccini JP, Wojdyla D, Becker RC, Halperin JL, Nessel CC et al. Prevention of stroke and systemic embolism with rivaroxaban compared with warfarin in patients with non-valvular atrial fibrillation and moderate renal impairment. Eur Heart J 2011;32:2387-94.

29. Hohnloser SH, Hijazi Z, Thomas L, Alexander JH, Amerena J, Hanna M et al. Efficacy of apixaban when compared with warfarin in relation to renal function in patients with atrial fibrillation: insights from the ARISTOTLE trial. Eur Heart J 2012;33:2821-30.

30. Bohula EA, Giugliano RP, Ruff CT, Kuder JF, Murphy SA, Antman EM et al. Impact of renal function on outcomes with edoxaban in the ENGAGE AF-TIMI 48 trial. Circulation 2016;134:24-36.

31. Hijazi Z, Hohnloser SH, Andersson U, Alexander JH, Hanna M, Keltai M et al. Efficacy and safety of apixaban compared with warfarin in patients with atrial fibrillation in relation to renal function over time: insights from the ARISTOTLE randomized clinical trial. JAMA Cardiol 2016;1:451-60.
32. Fordyce CB, Hellkamp AS, Lokhnygina Y, Lindner SM, Piccini JP, Becker RC et al. On-treatment outcomes in patients with worsening renal function with rivaroxaban compared with warfarin: insights from ROCKET AF. Circulation 2016;134:37-47.

33. Steffel J, Hindricks G. Apixaban in renal insufficiency: successful navigation between the Scylla and Charybdis. Eur Heart J 2012;33:2766-8.

34. Reinecke H, Brand E, Mesters R, Schabitz WR, Fisher M, Pavenstadt $\mathrm{H}$ et al. Dilemmas in the management of atrial fibrillation in chronic kidney disease. J Am Soc Nephrol 2009;20:705-11.

35. Reinecke H, Engelbertz C, Schabitz WR. Preventing stroke in patients with chronic kidney disease and atrial fibrillation: benefit and risks of old and new oral anticoagulants. Stroke 2013;44:2935-41.

36. Herzog CA, Asinger RW, Berger AK, Charytan DM, Diez J, Hart RG et al. Cardiovascular disease in chronic kidney disease. A clinical update from Kidney Disease: improving Global Outcomes (KDIGO). Kidney Int 2011;80:572-86.

37. Efird LM, Mishkin DS, Berlowitz DR, Ash AS, Hylek EM, Ozonoff A et al. Stratifying the risks of oral anticoagulation in patients with liver disease. Circ Cardiovasc Qual Outcomes 2014;7:461-7.

38. Connolly SJ, Ezekowitz MD, Yusuf S, Eikelboom J, Oldgren J, Parekh A et al. Dabigatran versus warfarin in patients with atrial fibrillation. N Engl J Med 2009; 361:1139-51

39. Patel MR, Mahaffey KW, Garg J, Pan G, Singer DE, Hacke W et al. Rivaroxaban versus Warfarin in Nonvalvular Atrial fibrillation. N Engl J Med 2011;365 883-91.

40. Granger CB, Alexander JH, McMurray JJ, Lopes RD, Hylek EM, Hanna M et al. Apixaban versus warfarin in patients with atrial fibrillation. N Engl J Med 2011; 365:981-92.

41. Giugliano RP, Ruff CT, Braunwald E, Murphy SA, Wiviott SD, Halperin JL et al. Edoxaban versus warfarin in patients with atrial fibrillation. N Engl J Med 2013; 369: 2093-104.

42. Kubitza D, Roth A, Becka M, Alatrach A, Halabi A, Hinrichsen $\mathrm{H}$ et al. Effect of hepatic impairment on the pharmacokinetics and pharmacodynamics of a single dose of rivaroxaban, an oral, direct Factor $\mathrm{Xa}$ inhibitor. Br J Clin Pharmacol 2013;76:89-98.

43. Douxfils J, Ageno W, Samama CM, Lessire S, Ten Cate H, Verhamme P et al. Laboratory testing in patients treated with direct oral anticoagulants: a practical guide for clinicians. J Thromb Haemost 2018;16:209-19.

44. Douxfils J, Mullier F, Loosen C, Chatelain C, Chatelain B, Dogne JM. Assessment of the impact of rivaroxaban on coagulation assays: laboratory recommendations for the monitoring of rivaroxaban and review of the literature. Thromb Res 2012;130:956-66.

45. Douxfils J, Mullier F, Robert S, Chatelain C, Chatelain B, Dogne JM. Impact of dabigatran on a large panel of routine or specific coagulation assays. Laboratory recommendations for monitoring of dabigatran etexilate. Thromb Haemost 2012;107:985-97.

46. Pollack CV Jr, Reilly PA, van Ryn J, Eikelboom JW, Glund S, Bernstein RA et al. Idarucizumab for dabigatran reversal—full cohort analysis. N Engl J Med 2017 377:431-41.

47. Connolly SJ, Milling TJ, Eikelboom JW, Gibson CM, Curnutte JT, Gold A et al. Andexanet alfa for acute major bleeding associated with factor $X a$ inhibitors. $N$ Engl J Med 2016;375:1131-41.

48. Ansell JE, Bakhru SH, Laulicht BE, Steiner SS, Grosso M, Brown K et al. Use of PER977 to reverse the anticoagulant effect of edoxaban. N Engl / Med 2014; 371:2141-2.

49. Beyer-Westendorf J, Forster K, Pannach S, Ebertz F, Gelbricht V, Thieme C et al. Rates, management, and outcome of rivaroxaban bleeding in daily care: results from the Dresden NOAC registry. Blood 2014;124:955-62.

50. Tomaselli GF, Mahaffey KW, Cuker A, Dobesh PP, Doherty JU, Eikelboom JW et al. 2017 ACC expert consensus decision pathway on management of bleed ing in patients on oral anticoagulants: a report of the American College of cardiology task force on expert consensus decision pathways. J Am Coll Cardiol 2017 70:3042-67.

51. Douketis JD, Spyropoulos AC, Anderson JM, Arnold DM, Bates SM, Blostein M et al. The Perioperative Anticoagulant Use for Surgery Evaluation (PAUSE) Study for patients on a direct oral anticoagulant who need an elective surgery or procedure: design and rationale. Thromb Haemost 2017;117:2415-24.

52. Deharo JC, Sciaraffia E, Leclercq C, Amara W, Doering M, Bongiorni MG et al.; Coordinated by the Scientific Initiatives Committee of the European Heart Rhythm A. Perioperative management of antithrombotic treatment during implantation or revision of cardiac implantable electronic devices: the European Snapshot Survey on Procedural Routines for Electronic Device Implantation (ESS-PREDI). Europace 2016;18:778-84.

53. Sticherling C, Marin F, Birnie D, Boriani G, Calkins H, Dan GA et al. Antithrombotic management in patients undergoing electrophysiological procedures: a European Heart Rhythm Association (EHRA) position documen endorsed by the ESC Working Group Thrombosis, Heart Rhythm Society 
(HRS), and Asia Pacific Heart Rhythm Society (APHRS). Europace 2015;17: 1197-214.

54. Calkins H, Willems S, Gerstenfeld EP, Verma A, Schilling R, Hohnloser SH et al. Uninterrupted dabigatran versus warfarin for ablation in atrial fibrillation. N Engl J Med 2017;376:1627-36.

55. Cappato R, Marchlinski FE, Hohnloser SH, Naccarelli GV, Xiang J, Wilber DJ et al. Uninterrupted rivaroxaban vs. uninterrupted vitamin $\mathrm{K}$ antagonists for catheter ablation in non-valvular atrial fibrillation. Eur Heart J 2015;36:1805-11.

56. Calkins H, Hindricks G, Cappato R, Kim YH, Saad EB, Aguinaga L et al. 2017 HRS/EHRA/ECAS/APHRS/SOLAECE expert consensus statement on catheter and surgical ablation of atrial fibrillation: executive summary. Europace 2018;20: 157-208.

57. Di Biase L, Callans D, Hæusler KG, Hindricks G, Al-Khalidi H, Mont L et al. Rationale and design of AXAFA-AFNET 5: an investigator-initiated, randomized, open, blinded outcome assessment, multi-centre trial to comparing continuous apixaban to vitamin $\mathrm{K}$ antagonists in patients undergoing atrial fibrillation catheter ablation. Europace 2017;19:132-8.

58. Potpara TS, Larsen TB, Deharo JC, Rossvoll O, Dagres N, Todd D et al.; Scientific Initiatives Committee of European Heart Rhythm Association. Oral anticoagulant therapy for stroke prevention in patients with atrial fibrillation undergoing ablation: results from the First European Snapshot Survey on Procedural Routines for Atrial Fibrillation Ablation (ESS-PRAFA). Europace 2015;17:986-93.

59. Death NCEiPOa. The NCEPOD Classification of Intervention. http://www.ncepod. org.uk/classification.html (6 March 2018, date last accessed).

60. Levy JH, Ageno W, Chan NC, Crowther M, Verhamme P, Weitz Jl et al. When and how to use antidotes for the reversal of direct oral anticoagulants: guidance from the SSC of the ISTH. J Thromb Haemost 2016;14:623-7.

61. Albaladejo P, Bonhomme F, Blais N, Collet JP, Faraoni D, Fontana $\mathrm{P}$ et al. French Working Group on Perioperative Hemostatis. Management of direct oral anticoagulants in patients undergoing elective surgeries and invasive procedures: updated guidelines from the French Working Group on Perioperative Hemostasis (GIHP) - September 2015. Anaesth Crit Care Pain Med 2017;36: 73-6.

62. Beyer-Westendorf J, Gelbricht V, Forster K, Ebertz F, Kohler C, Werth S et al. Peri-interventional management of novel oral anticoagulants in daily care: results from the prospective Dresden NOAC registry. Eur Heart J 2014;35: 1888-96.

63. Majeed A, Agren A, Holmstrom M, Bruzelius M, Chaireti R, Odeberg J et al. Management of rivaroxaban- or apixaban-associated major bleeding with prothrombin complex concentrates: a cohort study. Blood 2017;130:1706-12.

64. Gwyn JCV, Thomas MR, Kirchhof P. Triple antithrombotic therapy in patients with atrial fibrillation undergoing percutaneous coronary intervention: a viewpoint. Eur Heart J Cardiovasc Pharmacother 2017;3:157-62.

65. Lopes RD, Li L, Granger CB, Wang TY, Foody JM, Funk M et al. Atrial fibrillation and acute myocardial infarction: antithrombotic therapy and outcomes. Am J Med 2012;125:897-905.

66. Piccini JP, Jones WS. Triple therapy for atrial fibrillation after PCI. N Engl J Med 2017;377:1580-2.

67. Vranckx P, Lewalter T, Valgimigli M, Tijssen JG, Reimitz P-E, Eckardt L et al. Evaluation of the safety and efficacy of an edoxaban-based antithrombotic regimen in patients with atrial fibrillation following successful percutaneous coronary intervention $(\mathrm{PCl})$ with stent placement: rationale and design of the ENTRUST-AF PCl trial. Am Heart J 196:105-12.

68. Alexander JH, Lopes RD, Thomas L, Alings M, Atar D, Aylward P et al. Apixaban vs. warfarin with concomitant aspirin in patients with atrial fibrillation: insights from the ARISTOTLE trial. Eur Heart / 2014;35:224-32.

69. Dans AL, Connolly SJ, Wallentin L, Yang S, Nakamya J, Brueckmann M et al. Concomitant use of antiplatelet therapy with dabigatran or warfarin in the Randomized Evaluation of Long-Term Anticoagulation Therapy (RE-LY) trial. Circulation 2013;127:634-40.

70. Xu H, Ruff CT, Giugliano RP, Murphy SA, Nordio F, Patel I et al. Concomitant use of single antiplatelet therapy with edoxaban or warfarin in patients with atrial fibrillation: analysis from the ENGAGE AF-TIMI48 trial. J Am Heart Assoc 2016;5:e002587.

71. Valgimigli M, Bueno H, Byrne RA, Collet JP, Costa F, Jeppsson A et al. 2017 ESC focused update on dual antiplatelet therapy in coronary artery disease developed in collaboration with EACTS: the Task Force for dual antiplatelet therapy in coronary artery disease of the European Society of Cardiology (ESC) and of the European Association for Cardio-Thoracic Surgery (EACTS). Eur Heart / 2018:39:123-260.

72. January CT, Wann LS, Alpert JS, Calkins H, Cigarroa JE, Cleveland JC Jr et al. ACC/AHA Task Force Members. 2014 AHA/ACC/HRS guideline for the management of patients with atrial fibrillation: a report of the American College of Cardiology/American Heart Association Task Force on practice guidelines and the Heart Rhythm Society. Circulation 2014;130:e199-267.
73. Cappato R, Ezekowitz MD, Klein AL, Camm AJ, Ma CS, Le Heuzey JY et al. Rivaroxaban vs. vitamin $\mathrm{K}$ antagonists for cardioversion in atrial fibrillation. Eur Heart J 2014;35:3346-55.

74. Goette A, Merino JL, Ezekowitz MD, Zamoryakhin D, Melino M, Jin J et al. Edoxaban versus enoxaparin-warfarin in patients undergoing cardioversion of atrial fibrillation (ENSURE-AF): a randomised, open-label, phase 3b trial. Lancet 2016;388:1995-2003.

75. Itainen S, Lehto M, Vasankari T, Mustonen P, Kotamaki M, Numminen A et al. Non-vitamin $\mathrm{K}$ antagonist oral anticoagulants in atrial fibrillation patients undergoing elective cardioversion. Europace 2017. doi: 10.1093/europace/eux116. [EPUB ahead of print: 10 July 2017].

76. Frederiksen AS, Albertsen AE, Christesen AMS, Vinter N, Frost L, Moller DS. Cardioversion of atrial fibrillation in a real-world setting: non-vitamin $\mathrm{K}$ antagonist oral anticoagulants ensure a fast and safe strategy compared to warfarin. Europace 2017. doi: 10.1093/europace/eux188. [EPUB ahead of print: 26 June 2017].

77. Johansson AK, Juhlin T, Engdahl J, Lind S, Hagwall K, Rorsman $C$ et al. Is one month treatment with dabigatran before cardioversion of atrial fibrillation sufficient to prevent thromboembolism? Europace 2015;17:1514-7.

78. Tse DM, Young L, Ranta A, Barber PA. Intravenous alteplase and endovascular clot retrieval following reversal of dabigatran with idarucizumab. I Neurol Neurosurg Psychiatry 2017. doi:10.1136/jnnp-2017-316449. [EPUB ahead of print: 6 October 2017].

79. Kermer P, Eschenfelder CC, Diener HC, Grond M, Abdalla Y, Althaus K et al. Antagonizing dabigatran by idarucizumab in cases of ischemic stroke or intracranial hemorrhage in Germany - A national case collection. Int J Stroke 2017;12 383-91.

80. Dietzel J, Piper SK, Ruschmann R, Wollboldt C, Usnich T, Hellwig S et al. Impact of pre-admission oral anticoagulation on ischaemic stroke volume, lesion pattern, and frequency of intracranial arterial occlusion in patients with atrial fibrillation. Europace 2017. doi: 10.1093/europace/eux333. [EPUB ahead of print: 20 November 2017].

81. Drouet L, Bal Dit Sollier C, Steiner T, Purrucker J. Measuring non-vitamin K antagonist oral anticoagulant levels: when is it appropriate and which methods should be used? Int / Stroke 2016;11:748-58.

82. Seiffge DJ, Traenka C, Polymeris AA, Thilemann S, Wagner B, Hert L et al. Intravenous thrombolysis in patients with stroke taking rivaroxaban using drug specific plasma levels: experience with a standard operation procedure in clinical practice. J Stroke 2017;19:347-55.

83. Saver JL, Goyal M, van der Lugt A, Menon BK, Majoie CB, Dippel DW et al. Time to treatment with endovascular thrombectomy and outcomes from ischemic stroke: a meta-analysis. Jama 2016;316:1279-88.

84. Nogueira RG, Jadhav AP, Haussen DC, Bonafe A, Budzik RF, Bhuva $P$ et al. Thrombectomy 6 to 24 hours after stroke with a mismatch between deficit and infarct. N Engl J Med 2018;378:11-21.

85. Albers GW, Marks MP, Kemp S, Christensen S, Tsai JP, Ortega-Gutierrez S et al.; DEFUSE 3 Investigators. Thrombectomy for stroke at 6 to 16 hours with selection by perfusion imaging. N Engl J Med 2018;378:708-18.

86. Wahlgren N, Moreira T, Michel P, Steiner T, Jansen O, Cognard C et al. Ean. Mechanical thrombectomy in acute ischemic stroke: consensus statement by ESO-Karolinska Stroke Update 2014/2015, supported by ESO, ESMINT, ESNR and EAN. Int J Stroke 2016;11:134-47.

87. Powers WJ, Rabinstein AA, Ackerson T, Adeoye OM, Bambakidis NC, Becker K et al.; American Heart Association Stroke Council. 2018 Guidelines for the early management of patients with acute ischemic stroke: a guideline for healthcare professionals from the American Heart Association/American Stroke Association. Stroke 2018;49:e46-110.

88. Purrucker JC, Wolf M, Haas K, Rizos T, Khan S, Dziewas R et al. Safety of endovascular thrombectomy in patients receiving non-vitamin $\mathrm{K}$ antagonist oral anticoagulants. Stroke 2016;47:1127-30.

89. Paciaroni M, Agnelli G, Falocci N, Tsivgoulis G, Vadikolias K, Liantinioti C et al. Early recurrence and major bleeding in patients with acute ischemic stroke and atrial fibrillation treated with non-vitamin-k oral anticoagulants (RAF-NOACs) study. J Am Heart Assoc 2017;6:e007034.

90. Ahmed N, Steiner T, Caso V, Wahlgren N. Recommendations from the ESOKarolinska Stroke Update Conference, Stockholm 13-15 November 2016. Eur Stroke J 2017;2:95-102.

91. Paciaroni M, Agnelli G, Falocci N, Caso V, Becattini C, Marcheselli S et al. Early recurrence and cerebral bleeding in patients with acute ischemic stroke and atrial fibrillation: effect of anticoagulation and its timing: the RAF study. Stroke 2015; 46:2175-82.

92. Hankey GJ. Intracranial hemorrhage and novel anticoagulants for atrial fibrillation: what have we learned? Curr Cardiol Rep 2014;16:480.

93. Hemphill JC 3rd, Greenberg SM, Anderson CS, Becker K, Bendok BR, Cushman $M$ et al.; American Heart Association Stroke Council; Council on Cardiovascular and Stroke Nursing; Council on Clinical Cardiology. Guidelines 
for the management of spontaneous intracerebral hemorrhage: a guideline for healthcare professionals from the American Heart Association/American Stroke Association. Stroke 2015;46:2032-60.

94. Kuramatsu JB, Gerner ST, Schellinger PD, Glahn J, Endres M, Sobesky J et al. Anticoagulant reversal, blood pressure levels, and anticoagulant resumption in patients with anticoagulation-related intracerebral hemorrhage. JAMA 2015;313: 824-36.

95. Brønnum Nielsen P, Larsen TB, Gorst-Rasmussen A, Skjøth F, Rasmussen LH, Lip GYH. Intracranial hemorrhage and subsequent ischemic stroke in patients with atrial fibrillation: a nationwide cohort study. Chest 2015;147:1651-8.

96. Korompoki E, Filippidis FT, Nielsen PB, Del Giudice A, Lip GYH, Kuramatsu JB et al. Long-term antithrombotic treatment in intracranial hemorrhage survivors with atrial fibrillation. Neurology 2017;89:687-96.

97. Nishimura M, Sab S, Reeves RR, Hsu JC. Percutaneous left atrial appendage occlusion in atrial fibrillation patients with a contraindication to oral anticoagulation: a focused review. Europace 2017. doi: 10.1093/europace/eux313. [EPUB ahead of print: 8 December 2017].

98. Ruff CT, Giugliano RP, Braunwald E, Hoffman EB, Deenadayalu N, Ezekowitz $M D$ et al. Comparison of the efficacy and safety of new oral anticoagulants with warfarin in patients with atrial fibrillation: a meta-analysis of randomised trials. Lancet 2014;383:955-62.

99. Eikelboom JW, Wallentin L, Connolly SJ, Ezekowitz M, Healey JS, Oldgren J et al. Risk of bleeding with 2 doses of dabigatran compared with warfarin in older and younger patients with atrial fibrillation: an analysis of the randomized evaluation of long-term anticoagulant therapy (RE-LY) trial. Circulation 2011;123:2363-72.

100. Kato ET, Giugliano RP, Ruff CT, Koretsune $Y$, Yamashita T, Kiss RG et al. Efficacy and safety of edoxaban in elderly patients with atrial fibrillation in the ENGAGE AF-TIMI 48 trial. J Am Heart Assoc 2016;5:e003432.

101. Hylek EM, D'Antonio J, Evans-Molina C, Shea C, Henault LE, Regan S. Translating the results of randomized trials into clinical practice: the challenge of warfarin candidacy among hospitalized elderly patients with atrial fibrillation. Stroke 2006;37:1075-80.

102. Man-Son-Hing M, Nichol G, Lau A, Laupacis A. Choosing antithrombotic therapy for elderly patients with atrial fibrillation who are at risk for falls. Arch Intern Med 1999;159:677-85.

103. Steffel J, Giugliano RP, Braunwald E, Murphy SA, Mercuri M, Choi Y et al. Edoxaban versus warfarin in atrial fibrillation patients at risk of falling: eNGAGE AF-TIMI 48 analysis. J Am Coll Cardiol 2016;68:1169-78.

104. Rao MP, Vinereanu D, Wojdyla DM, Alexander JH, Atar D, Hylek EM et al.; Apixaban for Reduction in Stroke Other Thromboembolic Events in Atrial Fibrillation Investigators. Clinical outcomes and history of fall in patients with atrial fibrillation treated with oral anticoagulation: insights from the ARISTOTLE Trial. Am J Med 2018;131:269-75.

105. Hanon O, Assayag P, Belmin J, Collet JP, Emeriau JP, Fauchier L et al.; French Society of Geriatrics and Gerantology; French Society of Cardiology. Expert consensus of the French Society of Geriatrics and Gerontology and the French Society of Cardiology on the management of atrial fibrillation in elderly people. Arch Cardiovasc Dis 2013;106:303-23.

106. Sherrington C, Whitney JC, Lord SR, Herbert RD, Cumming RG, Close JC. Effective exercise for the prevention of falls: a systematic review and meta-analysis. J Am Geriatr Soc 2008;56:2234-43.

107. Tricco AC, Thomas SM, Veroniki AA, Hamid JS, Cogo E, Strifler L et al. Comparisons of interventions for preventing falls in older adults: a systematic review and meta-analysis. JAMA 2017;318:1687-99.

108. Fumagalli S, Potpara TS, Bjerregaard Larsen T, Haugaa KH, Dobreanu D, Proclemer $\mathrm{A}$ et al. Frailty syndrome: an emerging clinical problem in the everyday management of clinical arrhythmias. The results of the European Heart Rhythm Association survey. Europace 2017;19:1896-902.

109. Stangier J, Rathgen K, Stahle H, Gansser D, Roth W. The pharmacokinetics, pharmacodynamics and tolerability of dabigatran etexilate, a new oral direct thrombin inhibitor, in healthy male subjects. Br J Clin Pharmacol 2007;64:292-303.

110. Stangier J, Stahle H, Rathgen K, Fuhr R. Pharmacokinetics and pharmacodynamics of the direct oral thrombin inhibitor dabigatran in healthy elderly subjects. Clin Pharmacokinet 2008;47:47-59.

111. Liesenfeld KH, Lehr T, Dansirikul C, Reilly PA, Connolly SJ, Ezekowitz MD et al. Population pharmacokinetic analysis of the oral thrombin inhibitor dabigatran etexilate in patients with non-valvular atrial fibrillation from the RE-LY trial. J Thromb Haemost 2011;9:2168-75.

112. Kubitza D, Becka M, Zuehlsdorf M, Mueck W. Body weight has limited influence on the safety, tolerability, pharmacokinetics, or pharmacodynamics of rivaroxaban (BAY 59-7939) in healthy subjects. J Clin Pharmacol 2007;47:218-26.

113. Mueck W, Lensing AW, Agnelli G, Decousus H, Prandoni P, Misselwitz F. Rivaroxaban: population pharmacokinetic analyses in patients treated for acute deep-vein thrombosis and exposure simulations in patients with atrial fibrillation treated for stroke prevention. Clin Pharmacokinet 2011;50:675-86.
114. Upreti VV, Wang J, Barrett YC, Byon W, Boyd RA, Pursley J et al. Effect of extremes of body weight on the pharmacokinetics, pharmacodynamics, safety and tolerability of apixaban in healthy subjects. Br J Clin Pharmacol 2013;76:908-16.

115. Yin OO, Tetsuya K, Miller R. Edoxaban population pharmacokinetics and exposure-response analysis in patients with non-valvular atrial fibrillation. Eur J Clin Pharmacol 2014;70:1339-51.

116. Martin K, Beyer-Westendorf J, Davidson BL, Huisman MV, Sandset PM, Moll S. Use of the direct oral anticoagulants in obese patients: guidance from the SSC of the ISTH. J Thromb Haemost 2016;14:1308-13.

117. Burnett AE, Mahan CE, Vazquez SR, Oertel LB, Garcia DA, Ansell J. Guidance for the practical management of the direct oral anticoagulants (DOACs) in VTE treatment. J Thromb Thrombolysis 2016;41:206-32.

118. Breuer L, Ringwald J, Schwab S, Kohrmann M. Ischemic stroke in an obese patient receiving dabigatran. N Engl J Med 2013;368:2440-2.

119. Safouris A, Demulder A, Triantafyllou N, Tsivgoulis G. Rivaroxaban presents a better pharmacokinetic profile than dabigatran in an obese non-diabetic stroke patient. / Neurol Sci 2014;346:366-7.

120. Sandhu RK, Ezekowitz J, Andersson U, Alexander JH, Granger CB, Halvorsen S et al. The 'obesity paradox' in atrial fibrillation: observations from the ARISTOTLE (Apixaban for Reduction in Stroke and Other Thromboembolic Events in Atrial Fibrillation) trial. Eur Heart J 2016;37:2869-78.

121. Agnelli G, Buller HR, Cohen A, Curto M, Gallus AS, Johnson M et al. Oral apixaban for the treatment of acute venous thromboembolism. N Engl J Med 2013; 369:799-808.

122. Balla SR, Cyr DD, Lokhnygina Y, Becker RC, Berkowitz SD, Breithardt G et al. Relation of risk of stroke in patients with atrial fibrillation to body mass index (from patients treated with rivaroxaban and warfarin in the rivaroxaban once daily oral direct factor $\mathrm{Xa}$ inhibition compared with vitamin $\mathrm{K}$ antagonism for prevention of stroke and embolism trial in atrial fibrillation trial). Am J Cardiol 2017;119:1989-96.

123. Braekkan SK, van der Graaf Y, Visseren FL, Algra A. Obesity and risk of bleeding: the SMART study. J Thromb Haemost 2016;14:65-72.

124. Van Eijkeren MA, Christiaens GC, Sixma J], Haspels AA. Menorrhagia: a review. Obstet Gynecol Surv 1989;44:421-9.

125. Huq FY, Tvarkova K, Arafa A, Kadir RA. Menstrual problems and contraception in women of reproductive age receiving oral anticoagulation. Contraception 2011;84:128-32.

126. Stollberger C, Finsterer J. Interactions between non-vitamin $\mathrm{K}$ oral anticoagulants and antiepileptic drugs. Epilepsy Res 2016;126:98-101.

127. Raskob GE, van Es N, Verhamme P, Carrier M, Di Nisio M, Garcia D et al. Edoxaban for the treatment of cancer-associated venous thromboembolism. N Engl J Med 2018;378:615-24.

128. Posch F, Konigsbrugge O, Zielinski C, Pabinger I, Ay C. Treatment of venous thromboembolism in patients with cancer: a network meta-analysis comparing efficacy and safety of anticoagulants. Thromb Res 2015;136:582-9.

129. Brunetti ND, Gesuete E, De Gennaro L, Correale M, Caldarola P, Gaglione A et al. Direct oral anti-coagulants compared with vitamin-K inhibitors and lowmolecular-weight-heparin for the prevention of venous thromboembolism in patients with cancer: a meta-analysis study. Int / Cardiol 2017;230:214-21.

130. Short NJ, Connors JM. New oral anticoagulants and the cancer patient. Oncologist 2014;19:82-93.

131. Jones M, McEwan P, Morgan CL, Peters JR, Goodfellow J, Currie C). Evaluation of the pattern of treatment, level of anticoagulation control, and outcome of treatment with warfarin in patients with non-valvar atrial fibrillation: a record linkage study in a large British population. Heart 2005;91:472-7.

132. Van Spall HG, Wallentin L, Yusuf S, Eikelboom JW, Nieuwlaat R, Yang S et al. Variation in warfarin dose adjustment practice is responsible for differences in the quality of anticoagulation control between centers and countries: an analysis of patients receiving warfarin in the randomized evaluation of long-term anticoagulation therapy (RE-LY) trial. Circulation 2012;126:2309-16.

133. Wallentin L, Yusuf S, Ezekowitz MD, Alings M, Flather M, Franzosi MG et al. L. Efficacy and safety of dabigatran compared with warfarin at different levels of international normalised ratio control for stroke prevention in atrial fibrillation: an analysis of the RE-LY trial. Lancet 2010;376:975-83.

134. Fitzmaurice DA, Hobbs FD, Murray ET, Holder RL, Allan TF, Rose PE. Oral anticoagulation management in primary care with the use of computerized decision support and near-patient testing: a randomized, controlled trial. Arch Intern Med 2000; 160:2343-8.

135. Wilson SJ, Wells PS, Kovacs MJ, Lewis GM, Martin J, Burton E et al. Comparing the quality of oral anticoagulant management by anticoagulation clinics and by family physicians: a randomized controlled trial. CMAJ 2003;169:293-8.

136. Heneghan CJ, Garcia-Alamino JM, Spencer EA, Ward AM, Perera R, Bankhead C, Alonso-Coello P, Fitzmaurice D, Mahtani KR, Onakpoya IJ. Self-monitoring and self-management of oral anticoagulation. Cochrane Database Syst Rev 2016;7 CD003839. 